\title{
Y, SI PIDEN POR LA RADIO ES PORQUE ALGÚN DEFECTO TIENEN. EL VALOR DE LAS REDES EN EL MUNDO LABORAL DE LOS TRABAJADORES RURALES TEMPORARIOS
}

\author{
Mariela Blanco $^{1}$ y Dora Jiménez ${ }^{2}$
}

\section{Introducción}

A partir de la observación de la relación que se establece entre los individuos y el mundo del trabajo nos proponemos analizar en este artículo las redes resultantes de dicha relación. Estas redes resultan apropiadas pues su carácter intrínsecamente dinámico permite descubrir el movimiento de componentes estructurales tanto del mundo del trabajo como de los aspectos sociales.

Al hablar de redes hablamos de sociabilidad y, por lo tanto, de vínculos entre las personas que van conformando el entramado social. La mirada en la red pretende superar el análisis estático del individuo y del lugar que ocupa en la estructura social. Numerosos autores se han ocupado de dar cuenta de esta mirada especial hacia las relaciones sociales.

En esa línea Ramella (1995) valora el enfoque de las redes por tratarse de un concepto que tiene un status científico preciso y que ha introducido valiosas innovaciones en el campo de las ciencias sociales al considerar a la sociedad caracterizada por un conjunto de relaciones o de "configuraciones móviles", en oposición a una visión de la sociedad definida por un conjunto de categorías “construidas a priori, de una vez y para siempre".

De esta forma, "la fisonomía social de los individuos fue definida a partir de las relaciones sociales que éstos entrelazan y activan” (Ramella, 1995: 16). Es fundamental interrogarse sobre los modos "en que las relaciones crean solidaridad y alianzas, conformando finalmente los grupos sociales". Esta interdependencia con sus pares influye en los objetivos que se proponen y guían su acción. La importancia dada a las redes no significa negar el rol de la cultura sino, más bien, abrirse a un concepto dinámico de la misma "en tanto proceso creativo y permanente de construcción y reconstrucción que acontece en la interacción entre los individuos” (Ramella, 1995: 16).

Por su parte, Requena Santos interpreta a la red como el campo relacional total de una persona que tiene una representación espacio-temporal (Requena Santos, 1991).

\footnotetext{
${ }^{1}$ Consejo Nacional de Investigaciones Científicas y Técnicas, Argentina

${ }^{2}$ Consejo Nacional de Investigaciones Científicas y Técnicas, Argentina
} 
El análisis de redes enfatiza las relaciones que conectan la posición social dentro de un sistema y da una visión global de la estructura social y sus componentes (Requena Santos, 1991).

En otra perspectiva, que analiza a los sectores socialmente comprometidos o en riesgo, se considera que toda estructura social está compuesta por una red de relaciones sociales que existen en la realidad (Lomnitz, 1975). La autora se ocupa especialmente de un tipo de red social definido por relaciones de intercambio que se oponen a las relaciones más formales centradas en el mercado o la redistribución de bienes y servicios. El conjunto de redes de intercambio constituye una estructura social fluida y adaptable a distintas situaciones. Es la medida del flujo recíproco de bienes y servicios, tanto en cantidad y frecuencia como en su valor social en un intervalo de tiempo dado. En esta línea la informalidad puede ser vista como un elemento intrínseco de la formalidad en cuanto que es una respuesta a las deficiencias de esta última. La intensidad del intercambio es una variable subyacente a las redes. (Lomnitz, 1994; $1990 ; 1975)$.

Desde un enfoque más restrictivo Elisabeth Bott identifica a las relaciones externas de todas las familias bajo la forma de red. Al analizar estudios de tipo antropológico afirma que estos han examinado el proceso de ida y vuelta mediante el cual las relaciones de la familia nuclear influyen sobre la más amplia urdimbre del parentesco y por cuya mediación la misma ejerce una presión sobre la urdimbre de la familia. Si bien su interés se centra en el estudio de redes de familias urbanas, la autora hace ciertas disquisiciones sobre las diferencias entre estas familias y las rurales. Contrariamente a lo que ocurre en los grupos organizados, en las redes no todos los individuos que la integran mantienen relaciones sociales entre sí, las unidades externas que la componen no forman un todo social más amplio, no están rodeadas por un límite común (Bott, 1990).

En los estudios sobre trabajo rural se encuentra una amplia bibliografía que utiliza el concepto de redes para analizar algunas particularidades del empleo rural. En general, son investigaciones que abordan la importancia de las redes o lazos sociales como articuladoras de los procesos migratorios del trabajo rural. Estas redes se identifican como nexos vitales en la unión entre el lugar de origen y el lugar de destino de la mano de obra. A través de ellas se sustenta una serie de elementos como los lazos afectivos, de parentesco, diferentes canales de información, etcétera, que permiten conectar a la oferta y demanda de estos mercados de trabajo específicos. Las redes 
aseguran ese movimiento y son parte constitutiva de los procesos migratorios. (Boyd, 1989; Tenencia, 2007; García, 2005; Fazito, 2005).

La particularidad que intenta destacar el trabajo que presentamos es que las redes no sólo se actualizan entre distancias y espacios algunas veces divergentes, sino que constituyen un soporte fundamental para un determinado tipo de mercado de trabajo y de trabajadores aún en instancias locales. Las redes sustentan el ingreso, y la permanencia o la ausencia en el mercado laboral. Igualmente, se busca analizar los distintos lazos que actualizan los trabajadores temporarios para construir su ciclo anual de trabajo (con entradas y salidas del mercado laboral) como, así también, aquellos otros que si bien no son exclusivos del ámbito laboral, se ponen en juego y en un mismo nivel de importancia cuando la posibilidad de inserción en el mercado de trabajo está ausente.

Por lo tanto, el concepto de red resulta útil para el estudio de relaciones sociales que tienen la particularidad de ser dinámicas, intermitentes y no estar necesariamente limitadas a un tiempo, una dirección y un espacio.

Sobre la base de un trabajo de campo, realizado en una zona caracterizada por mercados laborales altamente informales, con marcada estacionalidad en las ocupaciones, con presencia de intermediarios, con gran rotación ocupacional y meses sin trabajo que obedecen a la índole de las producciones, observamos que las distintas redes ubicadas en tres dimensiones diferentes, nos ayudan a explicar las relaciones sociales desplegadas en el mundo del trabajo. Estas dimensiones son: A) Redes vinculadas al mundo del trabajo: a) redes para acceder al trabajo y b) redes en el trabajo, B) Redes y otros recursos para "pasar el agosto" y C) La confianza como elemento integrador del mundo del trabajo. El conjunto de las redes analizadas no asume necesariamente un carácter patrimonial en algunos de los puntos que conectan, sino que más bien, que es el contenido de la red el que adquiere relevancia según la especificidad de las distintas dimensiones que componen el ciclo anual de los trabajadores temporarios del Valle de Uco. ${ }^{3}$

\footnotetext{
${ }^{3}$ El Valle de Uco está ubicado en la provincia de Mendoza de la Argentina, recostado al pie de la cordillera de los Andes. Comprende los departamentos de Tupungato, Tunuyán y San Carlos. Sus cualidades climáticas y la existencia de canales de riego lo hacen especialmente fértil para el desarrollo de cultivos vitícolas, frutales y hortícolas. En los últimos años los viñedos han sufrido un fuerte proceso de reconversión que ha provocado cambios importantes en la escala de producción como también en la demanda de trabajo. (Ver mapas al final del artículo)
} 


\section{Aspectos sociales en el mundo del trabajo enfocados a través de las redes}

Entendemos a la red social como un sistema de relaciones entre los actores (individuales o colectivos) a través de los cuales se intercambian bienes materiales, información, elementos simbólicos y afectivos. Estas relaciones se caracterizan por la regularidad, la cotidianeidad y los episodios de intrusión en el pasado, presente y futuro de cada actor. De esta manera un actor participa de diferentes redes según los aspectos de la vida que se observen.

Dado que uno de los objetivos de la investigación es la conformación de la 'oferta de trabajo', partimos de considerar que esta oferta no se define sólo en torno a las dimensiones puramente económicas (ingresos, calificaciones, habilidades, etcétera) si no que, además, entran en juego las condiciones sociales y culturales que la posibilitan.

"La teoría de redes puede ser muy útil para subsanar los límites de la teoría económica, ya que tiene en cuenta las situaciones de asociación, solidaridad, o comunicación, y los valores, el poder o el conflicto; junto con los procesos y las estructuras como rasgos de la realidad social que no pueden reducirse a cálculos de utilidad económica más las condiciones externas”. (Requena Santos, 2003: 11)

El enfoque de las redes sociales funda sobre la comprensión de los "lazos personales un nuevo marco de referencia teórica para el análisis macro del mercado”. Es la única forma de afrontar el problema de la conexión entre la oferta de trabajo y los individuos que accederán a él ya que esta conexión se da dentro de una trama de relaciones que funcionan como vías de transmisión de información. Desde esta perspectiva la información no es un bien disponible en el mercado sino que "los individuos tienen una información limitada, dependiente de sus redes de relaciones". (Ramella, 1995: 19)

En el caso del Valle de Uco, caracterizado por una demanda de trabajo inestable e intermitente, con escasa participación en el trabajo en blanco, los trabajadores y empleadores implementan un entramado de lazos que los ayudan a conectarse entre sí. Las características del trabajo en la zona, teñido de informalidad, promueven el uso de sistemas informales de diferentes formas que se adecuan o que sirven a las distintas situaciones (redes).

La estacionalidad de las actividades promueve la vigencia esporádica de alguno de esos lazos. La existencia de cuadrilleros interfiere en el contacto directo que podría establecerse entre ambos actores (empleador y empleado). La figura del contratista de viñas es otro elemento establecido en alguna parte de la red, generalmente en uno de los 
extremos, que usa ese entramado para conseguir la mano de obra que hace falta. El cambio de patrones a lo largo del año moviliza a los trabajadores a desplegar distintos tipos de redes según la estación, la actividad, el producto o la tarea que tiene vigencia en ese momento de manera de cubrir el espectro de los diferentes requerimientos de mano de obra que funcionan, ya sea en forma permanente o temporaria. Las redes tienen la flexibilidad necesaria como para adecuarse a estos distintos requerimientos.

Una de las formas sociales que nos permite observar esos aspectos socioculturales que ayudan a definir la conformación de la oferta de trabajo es la familia. Ésta, no es sólo una fuente endógena de relaciones sino también un nudo de interacciones con otras familias y otras formas sociales; ella misma es una forma social determinada y variada en sus características distintas del nivel del individuo por lo que se constituye en otro nivel de análisis.

La masa de relaciones establecidas al exterior de la familia puede observarse en dos niveles de análisis: por un lado, encontramos los lazos sociales cuyo vínculo está definido por el trabajo; por otro lado, en un mismo plano de importancia, aparecen todas aquellas relaciones que tienen que ver con dispositivos de subsistencia en sus diferentes formas. Este tipo de relaciones basadas en criterios de reciprocidad y solidaridad hacia el interior de una familia también se proyecta hacia el entorno social más o menos inmediato de las mismas ya sea ante la presencia de contingencias extremas (pérdida del trabajo, enfermedades o situaciones familiares particulares), o como parte de una estrategia de los hogares más o menos estabilizada. Esta expansión de la red familiar sin embargo podrá variar de acuerdo a las características del hogar (comenzando aunque no agotándose en su composición y tamaño) y de las oportunidades del contexto (Neiman, Blanco y Jiménez, 2004)

Nos pareció importante incluir la idea de la confianza porque sustenta y tiñe las distintas redes sociales. Entendemos por confianza a un tipo de contenido especial de las relaciones que nos permite profundizar en el tema de redes a partir de consideraciones tales como la experiencia de los actores y las expectativas para el futuro que van dando cuenta del mundo del trabajo y dan forma a su inserción.

A.- Redes vinculadas al mundo del trabajo

Redes para acceder al trabajo.

En este punto desarrollaremos las diferentes cualidades que tienen las redes para facilitar el acceso a las fuentes de trabajo por parte de aquellos actores inmersos en ellas. 
Independientemente de las características del contexto en que se encuentren estos lazos informales, la importancia que cobran al unir a aquellos que buscan trabajo con los que lo pueden proveer, los convierte en un elemento fundamental para analizar la relación entre el mundo del trabajo y los individuos.

En primer lugar, se puede observar que sirven como canales de circulación de información, de utilidad tanto para el trabajador como para el que da el trabajo pues cualquiera de las dos partes puede ser emisor o receptor. Esta función de la red permite, para ciertos autores, abaratar el costo que representa, en una estructura formal, acercar la oferta y la demanda de trabajo (Requena Santos, 1991). Por otra parte, otros autores rescatan la importancia de los costos que implica mantener los contactos informales necesarios para acceder a la información (Douglas, 1990).

En segundo lugar, en el plano de intercambio de información, es importante observar el lugar que ocupan los individuos dentro de la red, la densidad de estas últimas y el tipo de lazo que se establece entre los puntos. Que éstos sean fuertes o débiles, consanguíneos o de amistad, permanentes o esporádicos o que unan a actores ubicados lejos o cerca, determinan las posibilidades de recibir información útil para lograr empleo.

Redes en el trabajo.

En el proceso de trabajo las redes adquieren una fisonomía diferente que les es dada por la particularidad del espacio en que se desarrollan. Ese espacio es el del ámbito laboral y por lo tanto los puntos de la red lo constituyen determinados tipos de empleo u ocupaciones. Pero los vínculos de las redes se establecen o nutren de elementos presentes en otros lazos sociales como los familiares o de amistad. Los diferentes puntos de la red, en general empleadores y empleados, ponen de manifiesto las diferencias de poder en la red; es así que las actualizaciones de lazos provenientes de otros ámbitos hacia el proceso de trabajo pueden obedecer a estrategias de los mejor colocados en la estructura social (Cook, 2003).

En el trabajo distinguimos dos tipos de redes: las de ayuda y las de trabajo familiar en conjunto. Las primeras se desarrollan entre el patrón y los trabajadores. El tipo de contenido es material y está presente la obligación de la retribución. Esta serie de prestaciones exige un mínimo de recurso afectivo que Wolf denomina amistad instrumental. La carga afectiva permite sortear situaciones de desigualdad social. (Wolf, 1980). El segundo tipo de red se actualiza siempre y cuando los patrones mínimos de reciprocidad funcionen al interior del hogar. Se trata del trabajo que realiza la familia en 
determinada tarea, por ejemplo la cosecha, donde las solidaridades se traducen en organización de la tarea con el objetivo de obtener mayor ingreso. El vínculo de la relación laboral lo define el patrón con algún miembro pero la tarea es desarrollada por la familia en conjunto.

B.- Redes y otros recursos para "pasar el agosto"

En este punto desarrollaremos las diferentes formas de ayuda que se presentan a través de las distintas redes, en aquellos momentos en que la falta de trabajo (a la que se pueden agregar problemas de salud, sucesos familiares o cualquier tipo de imprevisto) pone en peligro el nivel de subsistencia. La falta de trabajo suele ser total durante algunos meses del invierno ("pasar agosto"), pero también estas redes y recursos se movilizan en épocas donde el trabajo es escaso: son más los días que permanecen en su casa que los que se encuentran ocupados.

Descender por debajo de la línea de ese nivel no significa necesariamente que peligre la sobrevivencia pues en el mismo juegan, no sólo la alimentación y el abrigo (a los que Scott denomina dimensión objetiva), sino también aquellas exigencias culturales que son imprescindibles en la vida de la gente. (Scout, 1976) En las ocasiones en que se pone en riesgo este equilibrio surge una serie de prácticas que permiten que el individuo pueda contar con cierta ayuda o compensación como para que este equilibrio no se rompa.

En un contexto de privaciones lo monetario tiene importancia pero se relativiza en el marco del mencionado carácter cíclico de sus economías y modos de vida, mientras que lo no monetario constituido sobre la base de sociabilidad y reciprocidad compite no sólo como respuesta a las privaciones sino que también genera relaciones diferentes conformando de esta manera determinado roles y tipos sociales y formas de organización social más amplias aunque de alcance local (Neiman, Blanco y Jiménez, 2004).

En primer lugar, se recurre a la autoayuda que implica ahorro, reducción de gastos y búsqueda de ingresos con trabajos circunstanciales o "changas".

En segundo lugar, aparecen los lazos o redes que se desarrollan en distintos planos: familiares, de amistad o vecindad y laboral, que abarcan tanto a ex compañeros de trabajo como a ex patrones. En estos planos aparecen las prácticas de reciprocidad que tienen diferentes exigencias según la relación que el individuo posea con los distintos niveles. 
Es importante señalar que, cuanto más segura es cada una de las opciones de reciprocidad, menos recursos posee. La ayuda de los parientes cercanos es la más confiable pero éstos se encuentran en la misma situación de carencia que el necesitado. Aquellos que poseen más recursos generalmente ocupan un lugar distanciado en la sociedad, de manera que no siempre se puede esperar su asistencia.

La obligación de devolución se presenta en las dos opciones. Con los familiares porque sus necesidades son semejantes y surgen en la misma época y, con aquellas personas ubicadas en situaciones sociales alejadas, porque la distancia de la relación no permite dilatar la retribución.

C.- La confianza como elemento integrador del mundo del trabajo

Partimos de la idea de confianza de Luhmann que se entiende como la base de todo orden social. La relación de confianza se funda entre el cúmulo de experiencias y las posibilidades a futuro en perspectiva de expectativas que se actualizan en el presente. Por lo tanto toda relación social es acompañada por una carga de confianza. (Luhmann, 2005) Los principales elementos de la confianza son las normas y el compromiso. Las normas comprenden las reglas formales de funcionamiento como también las pautas no regladas que surgen de contextos culturales y simbólicos específicos pero no por eso menos efectivas. (Cook, 2003) El tipo de norma más generalizado es el compromiso que se funda en acuerdos explícitos de reciprocidad. (Balbi, 1995)

Por lo tanto, si bien esta relación se encuentra generalizada en todo el orden social, nos interesa observar los sentidos, contenidos y dinámicas que adquiere en el mundo del trabajo. Se ponen en juego las distintas normas (formales o informales) en función de las expectativas y compromisos de las relaciones laborales analizadas.

\section{A. Redes vinculadas al mundo del trabajo ${ }^{4}$}

a. Redes para acceder al trabajo

Los lazos establecidos entre los diferentes puntos de la red tienen múltiples funciones. Una de ellas es la de facilitar el acceso al trabajo. En esa función es primordial la circulación de información en diferentes sentidos: búsqueda de información por parte de las personas sin trabajo, el brindar información al interesado

\footnotetext{
${ }^{4}$ Los testimonios sobre la base de los cuales realizamos esta investigación fueron recogidos en un trabajo de campo realizado en febrero de 2008 en el Valle de Uco, Mendoza. Se entrevistaron familias locales, que viven en zonas urbanizadas. Los jefes de las mismas son trabajadores temporarios o permanentes del sector agropecuario.
} 
por parte de patrones, familiares y amigos, la recomendación de familiares, amigos o patrones que, de alguna manera, se hacen responsables de la actuación del que pide trabajo, etcétera.

Diversos autores consideran que el tipo de red que se cree, para obtener empleo y permanecer en él, es más importante que las condiciones estructurales existentes (Ramella, 1995). Requena Santos acentúa la importancia de los elementos informales y parte de la hipótesis de que las redes sociales constituyen "el más poderoso filtro selectivo de la movilidad y asignación ocupacional" y facilitan el movimiento de individuos al interior del mercado de trabajo. Influyen de tal forma sobre este mercado que implican la reducción de los costos de búsqueda y abaratan los costos de movilidad y desplazamientos. (Requena Santos, 1991: 4)

Al analizar el problema de la conexión entre trabajo disponible e individuos que acceden a él, Franco Ramella insiste en que "sólo puede ser afrontado si se reconoce que la demanda y la oferta entran en contacto en el interior de una trama de relaciones a través de las cuales la información sobre el trabajo disponible es adquirida por los individuos". Por lo tanto, son las relaciones personales, en tanto canales de transmisión de la información, las que determinan 'quién' tomará 'cuál' trabajo. En oposición a la teoría neoclásica del mercado que no tenía en cuenta el problema de la información pues suponía que el individuo cuenta con información total y perfecta, Ramella afirma que “la información no es un bien 'libre' en el mercado, disponible para todos en la misma medida" sino que "los individuos tienen una información limitada, dependiente de sus redes de relaciones". (Ramella, 1995: 19)

Mary Douglas, en su estudio sobre modelos de consumo y su relación con la inserción social de los individuos, parte de la base de que ser rico implica una red de relaciones mutuas difícil de romper y ser pobre es estar aislado. El acceso a la información es una forma de consumo y se ocupa del costo de la búsqueda de la misma en el mercado de trabajo. "La teoría de la competencia perfecta supone un conocimiento preciso del mercado pero por lo que hace a la cuestión laboral resulta más costoso estar al tanto de los precios alternativos sin el auxilio de la información..." (Douglas, 1990)

La circulación de información se realiza a través de lazos creados entre actores de status tanto semejantes como diferentes. En cualquiera de los dos casos pueden ser familiares, vecinos o amigos. El caso de los patrones ejemplifica bien a los lazos que unen actores de niveles distantes.

Esta información es vista como una ayuda. Dicen: la gente aquí es muy caritativa, la gente es buena y avisa, la gente ayuda. Hay que señalar que la recepción 
de la comunicación varía según el lugar que ocupa el actor dentro de la red y el tipo de lazos creados.

Oficinas de empleo, pocas hay acá. Todo se maneja así, llevándose. Uno va de acá para allá y conversa que aquí necesitan gente y de allá vienen.

La información que llega por los lazos que se establecen con los patrones o encargados de finca puede servir para dar empleo directo o para informar sobre otros patrones que necesitan gente.

Cuando el patrón que teníamos vendió la finca, el patrón que tenemos tenía la finca enfrente. Así que el patrón de la otra finca fue a hablar con mi esposo y lo trajo para que siguiera como contratista en la finca que tenía él. Así que seguimos ahí...

Podemos encontrar información de dispar importancia para los actores que necesitan acceder a un empleo, en diferentes tipos de redes, ya sean éstas más o menos densas, con lazos fuertes o débiles. Granovetter afirma que la existencia de estos últimos es de crucial importancia porque ofician de puente entre partes distantes del sistema social y permiten al individuo conocer oportunidades laborales procedentes de un entorno más amplio y de círculos sociales o status muy distintos al de su grupo cercano de familiares y amigos con los que comparte la misma información. (Granovetter, 2003; 2000)

Por otra parte, este autor observa que los lazos fuertes tienen más motivación para proporcionar ayuda y, normalmente, están disponibles con más facilidad.

En el mismo sentido, Scott habla de una relación inversa entre la disposición para dar ayuda y los recursos disponibles; coloca en un polo al Estado y a los patrones que cuentan con posibilidades de ayudar a los campesinos pero que, infrecuentemente, lo hacen y, en el otro polo, a los familiares cercanos que están siempre dispuestos a ayudar pero que comparten la misma situación de carencia. (Scout, 1976)

En general, el contenido de la información es variable: pueden notificar, no sólo de la vacante del trabajo sino también de la creación de nuevas fincas, de cuánto se paga el tacho en diferentes lugares, de características (virtudes y defectos) de los patrones, etcétera.

Existe también información que circula en sentido contrario. Un trabajador le habla a su patrón y le recomienda un allegado que trabaja bien. Es posible que él tenga prestigio frente al empleador $y$, de alguna forma se hace responsable por el que presenta. 
Se puede observar una circulación de información desde el trabajador hacia el patrón, sin necesidad de intermediario, en aquellos casos en que el interesado se presenta directamente en los lugares en los que se puede obtener trabajo, exponiendo su prestigio como empleado. En esos casos, Mary Douglas nos dice que "no se trata de acumular información sino de emitir información sobre uno mismo en los lugares adecuados". (Douglas, 1990)

Hay información que circula en forma indirecta, a través de intermediarios que pueden ser vecinos, amigos o familiares. Acá aparece, aunque poco (sólo dos casos), la radio como vehículo para ofrecer trabajo. No está bien considerada porque no da buena información y no se sabe en qué condiciones se va a trabajar.

Sí, a veces dicen por la radio "estamos necesitando", va y se lleva una clavada porque no es lo que le dicen... No le dicen el precio, ni las horas... Y, si piden por la radio es porque algún defecto tienen. Por eso no consiguen gente.

Un factor importante a tener en cuenta es el beneficio que reporta la rapidez en la obtención de la información y su adquisición de primera mano a través de un intermediario. Conocer fehacientemente, y en los primeros días de la cosecha, las condiciones en las que se trabajará (sobre todo el monto que se percibirá) permite al trabajador tener más posibilidades de elegir la finca en la que conchabará.

Trabaja con el mismo cuadrillero en lo que es durazno y lo que es la poda también. Pero, después, con la cosecha de uva no. Eso depende de dónde paguen un poquito más. Usted va y prueba un día y, al otro día recién le tiran la ficha en la finca. Le tiran el precio de la ficha. Tiene que estar, primero, un día trabajando y después recién le tiran el precio de la ficha. Nunca se lo dan antes. Y si le dan el precio de la ficha antes de ir a trabajar, tiene el precio viejo, del año pasado. O sea que trabaja con el precio del año pasado hasta que piden aumento o le tiran un precio nuevo.

En las redes, además de la circulación de información, pueden verse otros aspectos. Es importante ver el lugar que ocupan los actores dentro de la red y las relaciones que mantienen entre sí. Tener familiares que trabajan en una finca (ya sea como trabajadores comunes o como encargados) y están bien conceptuados sirve para conseguir trabajo allí.

Lo que pasa es que yo tengo un hermano que trabaja también en finca, así. Y mi hermano le dijo al mayor: “¿Che, querés trabajar? Vos sabés que van a ocupar” Y ahí nomás lo tomaron, así... Con decirle que lo tomaron y lo dejaron efectivo al mes.

$Y$, el más chico consiguió porque se fue a trabajar con un sobrino mío. Un sobrino mío tiene cuadrilla y agarró un trabajo en una finca de ahí enfrente, nomás. Y con la suerte que lo vieron trabajar a él y ya vino el encargado a buscarlo acá...Y lo vinieron y lo conquistaron. 
En el funcionamiento de las redes influyen las relaciones primarias: Acá nos conocemos todos porque nos hemos criado juntos. Cualquiera te da trabajo.

La importancia de las relaciones primarias se puede observar, también, en el caso de un chacarero boliviano que contrata gente esporádicamente.

\begin{abstract}
Siempre hay gente. Por una semana o dos semanas... Decimos a los parientes "vamos a cosechar" y vamos... Acá hay poca gente criolla. La mayoría estamos bolivianos. Ochenta por ciento hay aquí, en esta zona. Gente boliviana.... Cuando necesito tenés que tomar lo que haiga, pero la gente criolla, más que todo, va a la uva. Le gusta la uva. Durazno, uva.
\end{abstract}

Incide también el pasado de los actores. Cuando hay un conocimiento o amistad antigua (de los trabajadores o de sus padres) con el patrón, esto pesa para que se les de trabajo.

El patrón era vecino de nosotros, donde vivíamos. Desde chico nos conoce a nosotros... Porque nosotros íbamos a trabajar con el padre de él y él trabajaba y jugaba con nosotros..... Cuando él entró a la finca de él, como capataz, nos dio trabajo a nosotros. .. El papi sabía trabajar más en las fincas otras, nosotros sabíamos trabajar en la finca de él.

También se da el caso de los patrones que llaman primero para trabajar a aquellos que ya lo han hecho el año pasado.

Sí, todos los años. Para la poda y para el trabajo éste que estamos haciendo ahora, también. Somos unos de los primeros que entramos, los que hemos estado el año pasado. Si uno se quiere salir entonces entra otro más. Otro de los que no estaban. $Y$ ahí van quedando.

En cualquiera de estos casos pesa el prestigio de los trabajadores: lo buscan porque saben cómo trabaja.

Para contar siempre con posibilidades de trabajo el empleado mantiene ciertas normas de conducta como, por ejemplo, no cambiar de trabajo con frecuencia o sin motivo.

No, no siempre se consigue trabajo. Ahora, en esta temporada, sí. Adonde va uno tiene trabajo. En otro tiempo es difícil. Pero, por ahí, es lindo conseguir y quedarse en el mismo lugar. Uno no puede andar todas las semanas en distintos lugares. Acá trabajo hay mucho pero uno no puede andar cambiando porque, cuando te quedás sin trabajo, adonde vayás no te van a dar. Por abandonarle.

El cuadrillero es uno de los principales intermediarios, colocado en el medio de la red. Es común que éste busque una finca y luego elija a los trabajadores entre sus conocidos o que los trabajadores lo busquen a él porque saben que tiene posibilidades 
de dar empleo. En muchos casos se prefiere la conexión directa, obviando al cuadrillero, porque se siente que éste se queda con parte de la ganancia.

Y, sí. Porque el cuadrillero tiene la ganancia del viaje. El día se paga 50 o 48. Él se deja tres pesos todos los días. Nosotros íbamos al INTA y al viejo le pagaban 50 pesos al día. Y a nosotros nos pagaban 40. Cien pesos todos los días, se ganaba. Por llevarte nada más. No te conviene... Conviene más ir con el dueño de la finca y no con el cuadrillero.

A pesar de eso, con frecuencia se recurre al cuadrillero porque su cercanía social establece posibilidades de plantear una relación de confianza y lo hace más accesible.

\begin{abstract}
La primera vez que fui a buscar trabajo ahí me dijeron que no ocupaban más. Me dijo el encargado general. Entonces fui a un cuadrillero que estaba ahí trabajando y le pregunté si no había un lugarcito, aunque sea dos o tres días, que necesitaba alimentar a mi familia... Y este hombre me dice:" yo te voy a llevar y te voy a dar dos días de trabajo"...Y entré con él a trabajar y estábamos arrancando papas, no sabía cómo se hacía ese trabajo y lo aprendí acá. Y le gustó al cuadrillero, me dice, a la tarde, cuando terminamos, "no, vos no te vas más, vos vas a trabajar conmigo"
\end{abstract}

Hay que ver la circulación de información que se realiza desde el ego cuando éste sale a buscar trabajo (haya recibido información o no). Puede darse una doble circulación: el patrón envía información y el trabajador se acerca a él.

Las redes utilizadas para conseguir trabajo muchas veces son de uso intermitente. Todos los años, en la misma época, se contrata a la misma gente para la misma tarea.

Claro, te buscan los mismos. Ya te llaman. Capaz que viene el micro u otro que trabaja con nosotros y ya pasa avisando que nos van a venir a buscar. Para trabajar todos los años en la misma finca.

b. Redes en el trabajo

La particularidad que presenta este tipo de redes es que el espacio en que funcionan se circunscribe al ámbito laboral. Pero, a diferencia de las relaciones exclusivamente laborales propias del trabajo, esta red, para entrar en movimiento, también se nutre de otros lazos sociales como los personales, familiares o amistad. Por lo tanto, constituyen un tipo especial de red ya que operan en el espacio laboral pero se movilizan a través de la disponibilidad de otros recursos y, a la vez, son funcionales en distintos grados al desenvolvimiento del proceso de trabajo.

De esta manera los vínculos en la red se establecen entre empleadores y empleados. En estas situaciones se pone de manifiesto que las diferentes posiciones que ocupan los puntos de la red en la estructura social implican también diferencias de poder. Las actualizaciones de vínculos procedentes de otros ámbitos en el proceso de 
trabajo muchas veces obedecen a estrategias de los mejor colocados en esa estructura social (Cook, 2003).

Cabe destacar que, por la particularidad que encierran estos vínculos, participan trabajadores que actualizan en su trabajo redes que se sustentan y proceden de otros ámbitos. De esta forma, estos vínculos si bien son bastante generales no son comunes a todo el proceso de trabajo. A grandes rasgos podemos diferenciar dos tipos de redes: las de ayuda y las del trabajo familiar en conjunto. Las redes de ayuda son relaciones que se desarrollan entre el patrón y los trabajadores o entre los mismos trabajadores. El contenido de la red es de tipo material y, en general, está presente la obligación de la retribución. El tipo de vínculo que sustenta a estas redes determina diferentes posibilidades de poner en funcionamiento a la ayuda y también al contenido de la misma. Para Wolf determinados tipos de ayuda que se dan en el proceso de trabajo se pueden identificar con la idea de amistad instrumental y esta relación supone la existencia de un mínimo de recurso afectivo pero tiene como objetivo que se dé una amplia e indeterminada serie de prestaciones de ayuda mutua. Es decir, que frente a situaciones de desigualdad social o de poder, la carga afectiva puede considerarse como un instrumento para asegurar la continuidad de la relación. En el intercambio los dones del patrón son más inmediatamente tangibles (ayuda económica, protección), el otro, por su parte da en retribución bienes más intangibles como la demostración de estima y lealtades (Wolf, 1980).

Las redes de trabajo familiar presentan una situación especial porque los vínculos que la forman son estrictamente familiares pero se hacen evidentes en el proceso de trabajo. Nos encontramos aquí con la puesta en actividad de los componentes mínimos de reciprocidad que funcionan al interior de las familias. La red del trabajo en conjunto es la que determinaría, en la tarea donde se hace efectiva, la organización de ese proceso.

En relación a las redes de ayuda una primera distinción que podemos establecer entre las que se desarrollan en este ámbito tienen que ver con la ayuda del empleador. Esta ayuda se realiza sólo si existen vínculos de tipo personal y de interacciones cara a cara. En este tipo de red es frecuente la presencia de adelantos de dinero, la ayuda con mercadería y en algunos casos el permiso del patrón para desarrollar algún tipo de producción para el autoconsumo. A medida que las relaciones con los empleadores pierden el trato personal este tipo de red se diluye. 
mi papá sí, cuando trabaja en la finca. Porque es el patrón el mismo que le paga, que vive ahí y todo.

Si a mí me tocara, no me costaría nada ir al patrón y decirle: "Necesito dinero porque tengo..." Porque es así, yo voy y yo no tengo encargado, nada. Yo trato directamente con el patrón. No tengo encargado, no tengo administrador, nada. Como él también (el hijo), él trata directamente con el patrón.

En el caso de los adelantos de dinero es clave el pago directo del salario para poner en funcionamiento las redes de ayuda pues cuando los pagos se realizan por medio de cajeros automáticos o bancos se visualizan como limitantes para recurrir a este tipo de ayuda. De ahí la importancia de las relaciones cara a cara y personales con los patrones. Por lo tanto, a medida que se establecen relaciones de trabajo más formales se debilita la emergencia de redes de ayuda entre empleador y empleados. Es importante destacar que este tipo de relación es más frecuente entre los trabajadores que se encuentran empleados de forma permanente porque la red exige un período de tiempo amplio entre el momento de la ayuda y la retribución.

Igual, para el año pasado, para el invierno que llovía semanas enteras, él nos daba plata como que trabajábamos los días y después, de a poquito, nos iba descontando, no todo junto. A la semana, nosotros trabajábamos firme toda la semana y algunos se lo descontaban todo y él no, nos iba descontando de a poco.

Para los trabajadores la posibilidad de establecer redes con los patrones constituye una especie de seguridad de crédito hacia el futuro, sobre todo cuando se trata de solicitudes de adelanto para atender algún problema vinculado a la salud (de él o su familia). En el caso de los adelantos de dinero esta prestación se devuelve por medio de sucesivos descuentos pautados con el patrón. En algunos otros casos las retribuciones retornan con mayor trabajo por parte del trabajador (trabajar más horas en época de necesidad de los cultivos). En esta última situación a los tipos de lazos anunciados se le suma las situaciones afectivas o de amistad.

El tema es que confía en nosotros. Porque él nos conoce desde chico. El confía porque sabe que si no es hoy o mañana le vamos a devolver. Es como una gauchada que nos hace. Por ahí precisamos plata para llevar a mi mamá a tal lado y no tenemos plata, él viene y nos da la plata. Cuando él tiene apuro de que le preparen la tierra nosotros nos quedamos hasta más tarde y lo hacemos.

También para el caso de períodos con bajos días de ocupación este tipo de redes resulta importante para la subsistencia familiar, nos referimos a aquellas redes que contienen mercadería que entregan los patrones (frutas y verduras), que son 
aprovechadas por el hogar para alimento o preparar conservas para los 'momentos difíciles'.

\begin{abstract}
Nosotros en la finca hacemos una huerta grande para todo lo que es obrero de la finca. Se planta de todo lo que es verdura. Para todos los empleados. Para el patrón y para todos los empleados. Si quiere llevar algo de la huerta, se lleva. En la finca de lo que es la chacra se hace eso. Entre todos los mismos obreros los cuidamos. Eso es lo lindo, que por lo menos son todos unidos y pueden compartir las cosas. Como el patrón también lleva para el consumo de él compra todo junto con nosotros y si hace falta un tractor o algo, nosotros vamos y se lo pedimos y, a última hora, lo hacemos.
\end{abstract}

Un tipo especial de redes es aquel que se pone en funcionamiento en el momento de la cosecha, sobre todo de la uva, y que tiene que ver con el trabajo de la familia en conjunto. Este se desarrolla en el proceso de trabajo. En este nivel encontramos dos tipos de relaciones que conforman la red de trabajo en conjunto. Por un lado, aquellas relaciones propias de la familia que se sostienen bajo mecanismos de reciprocidad y ayuda mutua, que tienen como consecuencia la posibilidad de entrar en los mercados de trabajo para realizar tareas de forma grupal, por el otro lado, el tipo de empleo y retribución que facilita el desarrollo de este tipo de trabajo; nos referimos al empleo temporario y a las retribuciones a destajo. El empleo temporario en la cosecha demanda volúmenes importantes de mano de obra por pocos meses y en determinada época del año. La retribución a destajo es el pago que se realiza a los trabajadores por la cantidad de producto cosechado.

En el caso de trabajo grupal por parte de las familias la retribución es al conjunto de la familia y no de forma individual. La cantidad de miembros de un hogar trabajando determina mayores posibilidades de incrementar los ingresos. Al interior de la familia, la edad de los miembros, el sexo y el número de integrantes también va determinando diferentes organizaciones en la división del trabajo (por ejemplo, los hombres en general trasladan lo cosechado y tanto las mujeres como los niños realizan la recolección). Desde el punto de vista del hogar la posibilidad de realizar este tipo de trabajo se traduce en incrementos de ingresos y también, según la opinión de algunas mujeres, les permite trabajar y que los hijos las acompañen mientras realizan la tarea.

En la cosecha sí, nosotros vamos a las fincas, porque el patrón tiene otras fincas para el lado de Consulta y nosotros vamos. O sea, todos los contratistas del patrón, entre todos levantamos la cosecha. Vamos todos, con los hijos, con todo y cosechamos y así levantamos la cosecha. 
Se puede afirmar que en el lugar de trabajo se ponen de manifiesto distintos tipos de redes que tienen la particularidad de estar circunscriptas espacialmente a la actividad laboral y, por lo tanto se trata de vínculos entre ocupaciones y tipo de trabajadores, pero para su funcionamiento se erigen sobre la base de lazos que no son los laborales. Para Granovetter este tipo de lazo permite la conexión entre partes distantes del sistema social proporcionando información y recursos que están más allá de los disponibles en los propios círculos sociales (Granovetter, 2003). En cambio, cuando las relaciones se tornan más personalizadas o vienen por lazos de familia o amistad la presencia de los distintos tipos de redes expuestas es más fuerte. También siguiendo a Granovetter podemos inferir que la presencia de redes fuertes parece guardar relación tanto con la inseguridad económica como la falta de servicios sociales. Un punto interesante parecería ser que el tipo de ocupación (permanente o transitoria) también influye en los tipos de redes que se pueden encontrar en los procesos de trabajo. En la ocupación permanente se destacan las redes de ayuda del patrón en dinero o mercadería mientras que en las ocupaciones transitorias esas redes son menos intensas y predominan las de trabajo familiar.

\section{B. Redes y otros recursos para "pasar el agosto"}

Existe un conjunto de lazos que se desarrolla frente al surgimiento de distintas necesidades, como pueden ser aquellos originados en la ausencia o disminución del trabajo, problemas de salud, problemas familiares, fallecimientos, etcétera.

Los lazos se establecen en diferentes planos: familiar, vecinal y con compañeros de trabajo. Encontramos aquí a las redes de ayuda mutua, la reciprocidad y la donación, sistemas de ahorro, prácticas de autoconsumo y crédito, etcétera.

Como ya se ha visto, una de las características del calendario laboral, en esta zona, es la presencia de un período que abarca entre uno y tres meses del invierno, en que la oferta de trabajo es escasa, sobre todo para las mujeres. Para sobrevivir en ese período se desarrolla una serie de prácticas, algunas de ellas implementadas a través de redes establecidas con familiares o amigos.

Acá, el invierno, para la persona que no tiene trabajo, es muy crítico. Y más para la mujer, porque en el tiempo de invierno hay trabajo pero es de poda y la mayoría de las mujeres no sabe podar.

Los lazos denominados fuertes por Granovetter están constituidos por las relaciones familiares ya que los parientes son los más motivados para brindar ayuda 
(Granovetter, 2003). Los distintos miembros de la familia, especialmente hermanos y padres, pueden prestarle plata o mercadería, generalmente con un presupuesto firme de devolución porque, normalmente, la situación económica de los mismos es igual a la del que lo necesita.

Con ayuda de la familia. A veces nos prestaban plata y, cuando yo trabajaba, había que ir devolviendo de a poquito. Era quince días en un lado, un mes en otro... Y, así vive la gente acá.

Capaz que nos hacía falta un litro de aceite y ella (la madre) nos daba un litro de aceite. Mi suegra vive en la otra cuadra, necesitamos harina y bueno...Teníamos que devolver porque son mayores, no podíamos abusar de ellos.

Existe, también, la ayuda familiar con servicios (por ej. cuidado de los chicos) que, a veces, son retribuidos con dinero.

Mi mamá (me cuidaba los chicos), porque yo tenía mi mamá, así que... Yo le decía: "Mami, venite que quiero ir a trabajar unos días" y ella se venía. Después que ella falleció, ya no puedo trabajar afuera...

Si bien, frecuentemente, se hace hincapié en que la ayuda se solicita y se espera de la familia, hay casos en que los vecinos brindan servicios como préstamo de luz o facilitación de agua potable cuando alguien no puede acceder a los mismos.

Tengo una amiga que me pasa la luz. Vive en la otra cuadra. Y la señora de ahí nos pasa el agua... Y yo tengo que darle la mitad de la boleta. Ya la compartimos. Porque yo no puedo poner la pilata (de la luz) porque el terreno tiene deudas.

En muchos casos se manifiesta una firme resistencia a pedir ayuda, ya sea porque lo consideran "degradante" o porque saben que sus familiares no pueden brindarla. En ese caso, se trata de adecuar sus medios a la situación de emergencia. Entonces surgen las prácticas de ahorro de dinero o mercadería, durante los meses en que tienen más trabajo.

Nosotros ahorramos en mercadería. O sea, cobramos y compramos mercadería. Todos los fines de semana compramos. Esos tres meses, que no te toca ir a trabajar, tenés. Hemos pasado todo diciembre con la mercadería que teníamos... Y ahora vamos a tener que guardar, porque dicen que se va a poner feo el invierno este.

En esta zona es tradicional y está firmemente arraigada, la costumbre de envasar alimentos como tomate, verduras o frutas para tener algo para comer en esos momentos de necesidad. A veces plantan algo para poder envasar, por ejemplo tomates, duraznos o peras, aunque es frecuente que compren o les regalen los alimentos que envasarán. 
Nosotros hacemos muchos envasados. De tomate, de durazno, de berenjenas, todo eso. Nosotros antes decíamos que era un despelote, la envasada de tomate. Decíamos "vos vas con un peso y te comprás un tomate". Pero, si no tenés ese peso?

También se pudo observar el rechazo a pedir "fiado" al comerciante que los provee debido a que se recarga el precio de la mercadería y la obligación de pago mensual o semanal determina una falta constante de dinero en efectivo.

Sacamos una vez y después no sacamos más. Porque cuando cobrás no te alcanza ni siquiera para comprar para tener y tenés que pagar. No te conviene.

Las prácticas dirigidas al autoconsumo, como puede ser la confección de una huerta o la tenencia de animales de granja, no se presentaron con frecuencia. Se pudo observar un caso de cultivo en pequeña escala en la finca en que se actuaba como contratista y otro caso en que el dueño de la finca prestaba las herramientas necesarias y una superficie importante de tierra para hacer una huerta de la cual podían disponer los empleados. Estos ponían la semilla. De todos modos, la posesión de verdura para el consumo no les permite aislarse del consumo externo.

El tema de la ayuda del patrón, ya sea en mercadería que no vende o en adelanto de dinero sirve para subsistir en los momentos de menor trabajo o para superar circunstancias difíciles, está profundamente interrelacionado con la creación de lazos desiguales que ya se discutió en el punto de 'Redes en el trabajo'. También está determinado por la situación laboral del actor (transitorio o efectivo) ya que los lazos que se crean con el primero son más débiles que los armados con el segundo. Influye también el tipo de patrón (persona o empresa). En cualquier caso, el dinero adelantado debe devolverse, generalmente descontado del sueldo. En los casos en que hay una relación personal con el patrón, sobre todo si es antigua, no vacilan en pedirle dinero adelantado si surge una necesidad.

\section{La confianza como elemento integrador del mundo del trabajo}

La confianza es un tipo especial de relación social. Si bien a primera vista es común identificar a la confianza con lazos afectivos o con situaciones de contacto 'cara a cara' la confianza es más. Para Luhmann este tipo de relación social sustenta el orden social, ya que en este vínculo se ponen en juego las experiencias pasadas y las posibilidades a futuro en tanto expectativas. En este sentido en el lazo de confianza 
confluyen diferentes momentos de las historias de las relaciones sociales que se hallan involucradas (Luhmann, 2005).

Podemos identificar dos elementos que son específicos de la relación de confianza y se encuentran presenten en los diferentes tipos de intercambio de la misma: las normas y el compromiso. Para que las redes entren en movimiento entre los diferentes puntos que tocan es necesario que las acompañen determinados sistemas normativos. Las normas pueden ser de distinto tipo y comprenden tanto a las reglas de funcionamiento más estructural como a pautas y criterios que no se hallan regladas pero no por eso resultan menos efectivas en la eficacia de las redes (aspectos simbólicos y transmisión de información). La confianza es un tipo de relación social en donde el intercambio es explícitamente normativo y las normas se actualizan cada vez (Cook, 2003). Estos intercambios pueden ser de diferentes tipos y contenidos; constituyen la vida de la red por la cual circulan las relaciones. El tipo normativo más generalizado es el compromiso que supone un vínculo de reciprocidad con contenido de expectativas que se establecen en función de las relaciones por la cual circula la confianza (Balbi, 1995). Podemos observar que algunos niveles fuertes de compromiso que se visualiza en determinados vínculos de la confianza tienen consecuencias importantes sobre la estructura, en este caso, sobre el mundo del trabajo (Cook, 2003).

En relación a nuestro tema propuesto la confianza es analizada circunscripta al mundo del trabajo. Partimos de considerar dos puntos de esta relación que se establece en los sentidos de confianza entre trabajadores y patrones. En relación a esto indagamos sobre aspectos que tienen que ver con situaciones formales de las relaciones laborales; esto es, el cumplimiento de las obligaciones que establecen este vínculo. Entre otras consideramos a las formas de remuneración y puntualidad en el pago, la estabilidad en el trabajo, la presencia de aportes sociales, las formas de contratación, etcétera. Todas estas situaciones son interpeladas con respecto a la confianza o no de esa relación.

En primer lugar encontramos dos situaciones opuestas que canalizan y sustentan la confianza entre empleados y empleadores. Una primera, que se ejercita sobre la base de los vínculos 'cara a cara' o lo que es lo mismo en interacciones directas, tiene que ver con elementos afectivos, de familiaridad o vecindad. En este nivel no estamos frente a relaciones claramente estandarizadas, los derechos y expectativas que fundan la relación no están predeterminados en modo alguno y son característicamente variables y difusos. El patrón de reciprocidad que sigue cada relación depende exclusivamente de la historia de los contactos sociales ocurridos entre las personas que mantienen cada relación en particular; los efectos acumulativos de esos contactos conforman un proceso 
que genera el patrón vigente en cada momento de la historia de la relación (Balbi, 1995). Estos aspectos son los que canalizan y fundamentan la confianza con respecto al vínculo laboral.

Porque ya hacen varios años que estoy ahí así que creo que, más o menos, hay una confianza. Por lo menos charlamos. Se para, conversa conmigo.

En esta misma línea el trato directo con el patrón también hace de la relación de confianza un sentido positivo. La presencia de intermediarios de distintos tipo como cuadrilleros o cooperativas de trabajo son evaluadas como situaciones riesgosas y sin ningún tipo de confianza como para alimentar expectativas con respecto a los vínculos de trabajo.

Ahí tenés que tener cuidado. Tenés que anotar todo. Ahí creo que no. Si tenés que hacer una planta y, si dejás la mitad de la hilera tenés que contar la planta y anotarla. Porque después cuando vas a querer cobrar te van a decir, 'mirá tenés tantas hileras'y si no sabés cuántas tenías, si te pagaron bien, te pagaron, y si te pagaron mal ya fuiste.

Llamativamente, donde las relaciones laborales son más formales los mecanismos de confianza tienen una fuerza distinta. Prevalecen las situaciones de seguridad y fuertes expectativas en la continuidad en el trabajo. Es en este nivel donde la confianza se presenta en una especie de recta continua en el tiempo y sobre todo hacia adelante. Se visualizan como componentes centrales de la relación al pago en término y las constancias de seguros de salud y aportes jubilatorios.

Tenemos confianza en la empresa porque nos pagan puntual.

Tengo confianza porque un patrón cuando lo quiere ocupar, lo pone en los libros y le cumple.

En el caso del trato directo con el patrón también el tiempo tiene un rol fundamental pero, a diferencia de las relaciones más formales, ese tiempo es mucho más importante hacia atrás, es decir, por aquello que van formando los lazos afectivos, de familiaridad o vecindad. Se sostiene la confianza porque se conocen hace mucho tiempo, porque viven cerca del patrón, porque algún pariente ya trabajaba con ellos, etcétera.

$Y$, la manera de ser de él, o sea, yo se que el patrón, cuando uno lo necesita, a lo mejor, está. Y cuando nos puede dar una mano nos da. Nosotros tenemos un 
Por último, cabe destacar que por parte de los trabajadores existe una especie de valorización que hace posible el vínculo de la confianza. Estos valores se circunscriben al buen desempeño en el trabajo, al cumplimiento de los horarios, a la experiencia, etcétera. Mientras el patrón moviliza recursos para construir relaciones útiles o para brindar utilidad práctica a las relaciones ya existentes - les adelanta dinero, los ayuda en caso de enfermedad, etcétera-, el trabajador posee recursos más modestos pues no puede ofrecer más que la eficiencia y la regularidad de su trabajo (Balbi, 1995).

Sí, porque hace muchos años que trabajamos con ellos. Ellos te brindan la confianza si sos cumplidor. Lo que más le gusta a los patrones... Como a uno, si vos trabajás toda la semana completa y llega el sábado, te gusta que te paguen. Es mutua la confianza. Si trabajás toda la semana, el sábado te tienen que pagar a las doce, a la una, al horario que ellos digan. Ellos quieren que vos seas cumplidor con los días.

Las situaciones de desconfianza también se fundamentan sobre los niveles que hacen a la confianza. En los vínculos de tipo más personal la desconfianza se asocia con cierta reticencia por parte de los trabajadores a establecer lazos más estrechos del tipo confidencial. Pero, en su mayoría es la falta de cumplimiento por parte de los patrones o intermediarios con los acuerdos pautados, por ejemplo en los días de cobro, el monto de las remuneraciones, la existencia real de aportes, etcétera.

Para concluir podemos destacar que en el mundo del trabajo la relación de confianza comprende diferentes elementos, muchos de los cuales son ajenos a los canales de circulación propios de este mundo. Es así que tienen primacía relaciones afectivas, familiares y vecindad. En estos escenarios la confianza toma su fuerza de aquello que viene desde atrás y que se actualiza en el presente como componente del mercado de trabajo. Todo lo contrario sucede con las relaciones de confianza que se afianzan en los términos de vínculos laborales formales donde la continuidad de la relación está puesta en perspectiva a las expectativas de continuar y ser parte del mundo del trabajo. En esta situación la presencia de lazos como los arriba mencionados se diluye.

\section{Conclusiones}

En gran parte de la bibliografía que se ocupa del mercado de trabajo este concepto de red que analizáramos es utilizado para explicar las diferentes formas de acceder al empleo, en el caso de los trabajadores provenientes de comunidades ajenas al 
mismo. Frente a un mercado de trabajo altamente informal, como el que recorrimos en esta investigación, encontramos que las redes sociales de distinto tipo son funcionales al mismo aún en instancias locales. Esta funcionalidad se pudo observar en los distintos planos que hemos analizado.

En el plano de la búsqueda laboral las redes se mostraron eficientes por las posibilidades de acceso a la información y las cercanías que establecen con las fuentes de trabajo. Las redes cuentan con la flexibilidad necesaria para adaptarse a las distintas situaciones, que varían a lo largo del año en relación con los productos y tareas característicos de cada estación. En este aspecto nos encontramos con variadas formas de redes, según las situaciones laborales que se presentan y se puede observar el uso selectivo que se hace de los diferentes lazos, en función de las diversas situaciones presentadas.

Por otra parte, en el ámbito laboral observamos la presencia de redes que funcionan como mecanismos de apoyo para la organización del trabajo. En ese ambiente el sistema de ayuda desde el patrón hacia los empleados se ejecuta a través de redes cuyo contenido es de tipo "afectivo" mediante las cuales circulan elementos en los dos sentidos y la obligación de devolución no se discute.

A lo largo de nuestro trabajo, la familia se presentó como una institución que nos permitió observar aquellos aspectos socioculturales que influyen en la conformación de la oferta de trabajo. Representa un nivel de análisis diferente al de los individuos que la componen e interesa especialmente ver los lazos que establece con otras formas sociales y con otras familias que integran la comunidad. Al exterior de la familia se puede observar una red de relaciones en la que se establecen dos niveles de análisis: en primer lugar se encuentran los lazos cuyo vínculo está definido por el trabajo y en segundo lugar, aunque en un mismo plano de importancia, aparecen todos aquellos vínculos relacionados con los variados dispositivos de subsistencia que surgen cuando desaparece la oferta de empleo.

En este plano, que hemos denominado de subsistencia surgido en los tiempos en que no hay trabajo o aparecen necesidades circunstanciales, las redes cumplen un rol que, de alguna manera, es funcional al mundo del trabajo porque permiten superar esos momentos sin necesidad de salir a buscar empleo en otros lados. Pudimos observar que, frente a esta situación de necesidad, predomina el uso de redes familiares o fuertes mientras que los lazos débiles pasan a segundo plano.

De esta manera notamos que en los momentos de crisis prevalecen las tramas de los lazos familiares mientras que en situación de abundancia de trabajo aparecen los 
lazos individuales aunque siempre con el soporte de los vínculos fuertes (parentesco, vecindad, amistad, etcétera).

En la dimensión de la confianza en el mundo del trabajo, en tanto expectativas de los trabajadores, que analizamos en el texto, observamos que las redes que se ponen en movimiento contienen elementos normativos y de compromiso. En un contexto informal parecerían cobrar fuerza las redes con alto contenido afectivo y cercanía física y social. A medida que la inserción laboral es más formal los vínculos que se crean son más distantes. Por lo tanto, las expectativas laborales se fundan en los lazos fuertes así como en los débiles.

Para concluir, podemos destacar que el análisis de redes para el mercado de asalariados temporarios revela la presencia de interesantes canales de relación de diferentes tipos, a través de los cuales se trasmite la información necesaria para acceder al trabajo o para permanecer en él. Estos mismos canales sirven para la circulación de bienes mediante los cuales se expresa la solidaridad, principalmente entre pares pero también entre actores lejanos socialmente.

Un punto que se desprende del análisis de redes en el mundo del trabajo es que aunque el contenido de la red revista un carácter afectivo, recíproco o solidario hay ocasiones en que las distancias sociales - sobre todo en las relaciones de trabajoabsorben esos contenidos en función de las utilidades de ese mercado tal como lo hemos demostrado en este trabajo. De esta forma las redes son útiles para ver la relación entre los grupos sociales con sus diferentes características y el funcionamiento intermitente del mercado laboral.

Mapa 1: Provincia de Mendoza en la República Argentina

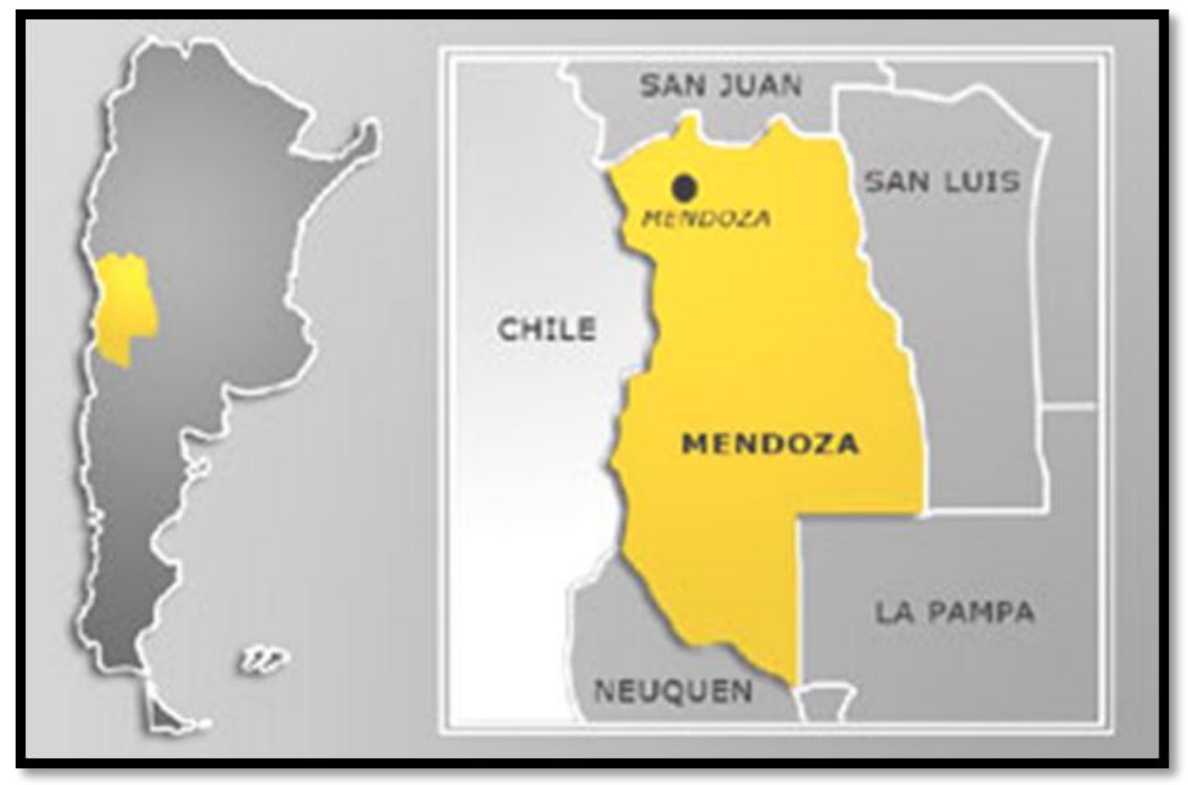




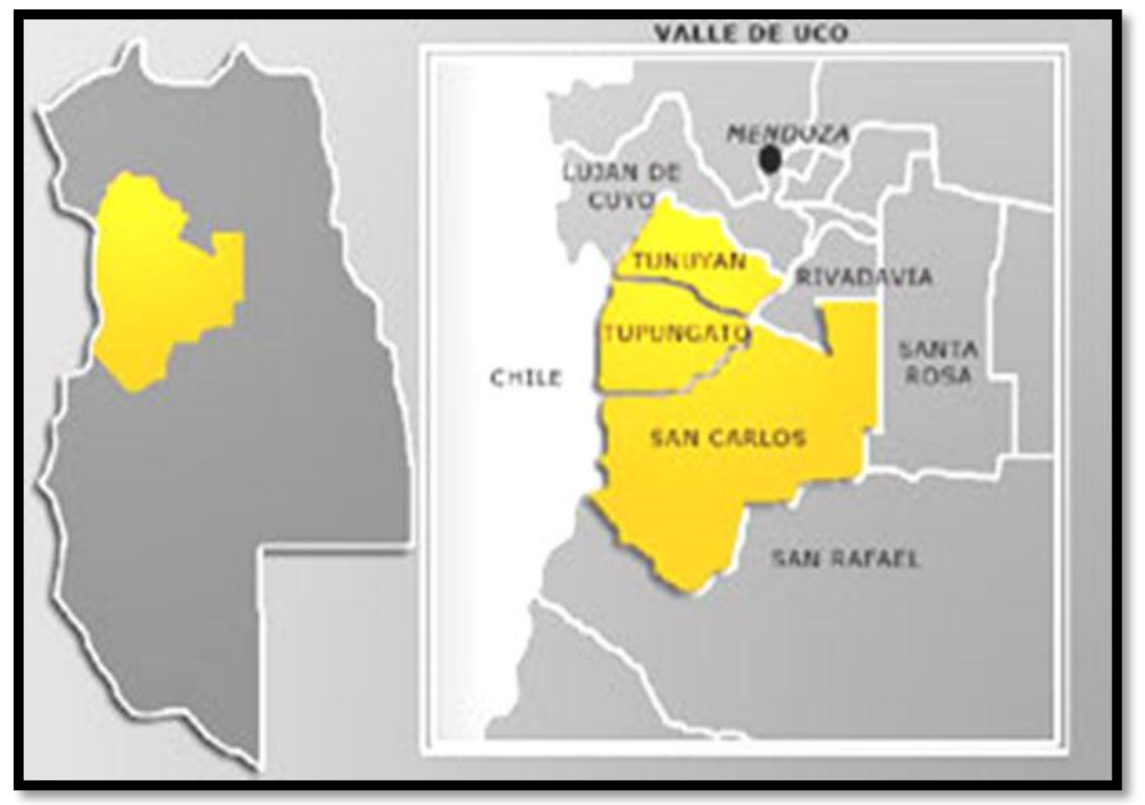

\section{Referências}

BALBI, Fernando Alberto. "Las paradojas de la regularidad. Algunas consideraciones en torno del papel de los intermediarios en el proceso productivo pesquero del área del Delta Entrerriano". In: TRINCHERO, Hugo (editor). Producción Doméstica y Capital. Estudios desde la antropología económica. Buenos Aires: Editorial Biblos, 1995. p. 139-170.

BANTON, Michael (compilador). Antropología social de las sociedades complejas.

Madrid: Alianza Editorial, 1980.

BENENCIA, Roberto. "Información y redes sociales en la conformación de mercados de trabajo". In: V Congreso Latinoamericano de Sociología del Trabajo, Hacia una nueva civilización del trabajo, Montevideo, 2007.

BOTT, Elizabeth. Familia y red social. Roles, normas y relaciones externas en las familias urbanas corrientes. Madrid: Taurus Humanidades, 1990.

BOYD, Mónica. "Family and personal networks in international migration: recent developments and new agendas". In: International Migration Review, vol. XXIII, $\mathrm{n}^{\circ} 3$. New York: Center for Migration Studies (CMS), 1989.

COOK, Karen S. "La vinculación de actores y estructuras desde la perspectiva de las redes de intercambio" In: Félix Requena Santos (compilador), Análisis de redes sociales. Orígenes, teorías y aplicaciones., Madrid: Centro de Investigaciones Sociológicas-Siglo XXI de España Editores, 2003. p. 478-497.

DOUGLAS, Mary y ISHERWOOD, Baron. El mundo de los bienes. Hacia una antropología del consumo. México: Editorial Grijalbo, 1990.

FAZITO, Dimitri. "A configuração estrutural dos arranjos familiares nos processos migratórios: a forca dos laços fortes para a intermediação". In: Seminário As famílias e as políticas públicas no Brasil, 21-22 novembro. ABEP, Belo Horizonte, Brasil, 2005.

GARCÍA, Carlos. "Buscando trabajo: Social networking among immigrants from Mexico to the United States". In: Hispanic Journal of Behavioral Sciences, vol. 27, $\mathrm{n}^{\circ}$ 1. Thousand Oaks: Sage Publications, 2005. 
GRANOVETTER, Mark S. "La fuerza de los vínculos débiles”. In: Política y Sociedad, 33. Madrid: Servicio de Publicaciones de la Universidad Complutense, 2000. p. 41-56. GRANOVETTER, Mark S. "La fuerza de los lazos débiles. Revisión de la teoría reticular”. In: SANTOS, Félix R. (compilador). Análisis de redes sociales. Orígenes, teorías y aplicaciones. Madrid: Centro de Investigaciones Sociológicas-Siglo XXI de España Editores, 2003. p. 196-230.

LOMNITZ, Larissa. Redes sociales, cultura y poder: ensayos de antropología latinoamericana. México: FLACSO-Miguel Ángel Porrúa, 1994.

LOMNITZ, Larissa. "Redes informales de intercambio en sistemas formales: un modelo teórico". In: Comercio Exterior, vol. 40, n 3. México: FLACSO-Miguel Ángel Porrúa, 1990. p. 212-220.

LOMNITZ, Larissa. Cómo sobreviven los marginados. México: Siglo XXI Editores, 1975.

LUHMAN, Niklas. Confianza. Barcelona: Anthropos Editorial, 2005.

MAYER, Adrian C. "La importancia de los cuasi-grupos en el estudio de las sociedades complejas". In: BANTON, Michael (compilador). Antropología social de las sociedades complejas. Alianza Editorial, Madrid, 1980. p. 108-133.

MURMIS, Miguel y FELDMAN, Silvio. "Formas de sociabilidad y lazos sociales". In: FELDMAN, Silvio (compilador). Sociedad y sociabilidad en la Argentina de los 90. Buenos Aires: Biblos, 2002.

NEIMAN, Guillermo; BLANCO, Mariela y JIMÉNEZ, Dora. "Desde abajo. La participación de las redes familiares y sociales en la subsistencia de los sectores rurales pobres". In: FORNI, Floreal H. (compilador). Caminos solidarios de la economía argentina. Redes innovadoras para la integración. Buenos Aires: Fundación CICCUS, 2004.

RAMELLA, Franco. "Por un uso fuerte del concepto de red en los estudios migratorios". In: BJERG, María y OTERO, Hernán (compilador). Inmigración y redes sociales en la Argentina moderna. Tandil: Instituto de Estudios Histórico-Sociales, IEHS - Centro de estudios migratorioslatinoamericanos, CEMLA, 1995. p. 9-34.

REQUENA SANTOS, Félix. Redes sociales y mercado de trabajo. Elementos para una teoría del capital relacional. Madrid: Centro de Investigaciones Sociológicas-Siglo XXI de España Editores, 1991.

REQUENA SANTOS, Félix (compilador). Análisis de redes sociales. Orígenes, teorías y aplicaciones. Madrid: Centro de Investigaciones Sociológicas-Siglo XXI de España Editores, 2003.

RODRÍGUEZ, Joseph A. Análisis estructural y de redes. Colección Cuadernos Metodológicos $n^{\circ}$ 16. Madrid: Centro de Investigaciones Sociológicas (CIS), 2005.

SAHLINS, Marshall. Economía de la Edad de Piedra. Madrid: Akal Editores, 1977.

SCOTT, James C. The Moral Economy of the Peasant. Rebellion and Subsistence in Southeast Asia. USA: Yale University Press, 1976.

WOLF, Eric R. "Relaciones de parentesco, de amistad y de patronazgo en las sociedades complejas". In: BANTON, Michael (compilador). Antropología social de las sociedades complejas. Madrid: Alianza Editorial, 1980. p. 19-39. 